\title{
Social Accounting vs Food Accessibility in Developing World
}

\author{
Mohammad Taghi Sheykhi* \\ Professor Emeritus of Sociology, Alzahra University, Tehran, Iran
}

*Corresponding author: Mohammad Taghi Sheykhi, Professor Emeritus of Sociology, Alzahra University, Tehran, Iran.

\author{
Received Date: August 12, 2019 \\ Published Date: September 10, 2019
}

\begin{abstract}
Social accounting is used as an umbrella term to denote better use of land and environment to extract food including plants, vegetables, animals etc. It provides better estimates of what there is, and what there should be. As nature is ever changing, there should be a supervision on such a link as to what we mean by social accounting. Human increase change in patterns of life and many more impact human consumption including food recipes. So, measuring the quantitative social and economic change that is happening, or about to happen, will help in stabilization of food products and items. Sociologically speaking, planners and policy makers must know that human behavior does not remain stable. According to change in human wants and aspirations, social accounting must be applied. Unfortunately, developing countries do not use social accounting, and the result of which is chaos in those countries including food issues and food shortages.
\end{abstract}

Keywords: Umbrella term; Nature; Human consumption; Food recipes; Human behavior; Economic health; Social accounting; Vulnerability; Food needs; Social management.

\section{Objective}

The aim of the present research is to represent the role of social accounting as an umbrella including demographic, social, cultural and environmental indicators/variables which bring about food health in countries. In the meantime, efficient management would be possible and attainable under the conditions of food health in any country. While the three social, cultural and environmental variables are a triangle being faced by the developing countries today, the quality and quantity of population also play an important and determining role, and shortage of which contributes to socioeconomic vulnerabilities, smuggling and drug addiction among a large number of people in developing world. The aforementioned variables have a pivotal role in accessing a healthy economic system.

\section{Population growth vs Food health}

Social accounting can play a determining role in population planning. Population growth rate has largely affected population structure in recent decades in the developing countries; a phenomenon leading to young population structure. While about $83 \%$ of the world population is residing in the developing world (WPDS, 2018) [1], social accounting is minimally associated with that, and that has resulted in increasing social abnormalities for those countries, leaving behind unemployment, poverty, unbridled migration, increasing deviances, increasing drug abuse etc. The current situation has caused $28 \%$ of population in the developing world remaining below 15 years of age. Such a scenario will encounter the countries of the developing world with a large bulk of unemployed youth in search of food in the years to come. However, the current situation is leading many developing countries to delayed marriages culminating in lower fertility within the youth of below 35 years of age [2].

Because of failures of social accounting many developing countries are surprisingly facing young populations whom cannot be easily fed and employed. Appropriate actions must usually be notified through social accounting, and that includes economic and industrial investments versus those newly born. Under such circumstances many of those born in 1980s and beyond are in poverty conditions in developing world. The scenario means that there is not economic independence and hiring opportunities for such people. The present circumstances as a motivation, moves the youth towards anti-social behaviors. Though the family institution in some countries like Iran tries to support such young unemployed youth, yet they are pulled toward drug addiction. 
Therefore, to modify the existing situation, and control its continuity for the years to come, population growth rate must be checked, and a coordination between population growth rate and creation of job opportunities need to be maintained. If that is not practiced, the youth should expect further deviations in the future. According to a socio-economic and demographic view, for every $1 \%$ of population growth, there should be $4 \%$ economic growth. Such a balance helps in not having unemployment and other dilemmas [3].

Though some developing countries have had declining population growth rates in recent years, yet the volume of young population has remained the same, and even some added to it (15+) every year. These youth potentially vulnerable, seriously need social accounting to be less jeopardizing the economy. However, an increasing number of the Third World countries are facing such a scenario. Hence, backgrounds for smuggling, human trafficking and the like are hereby set. Thus, to reach a healthy economy, the aforementioned destructive factors must be controlled, and eliminated. It must also be notified that the culture of drug deals could not be rooted out overnight.

Sociologically speaking, social accounting based on the current parameters would be a turning point to reach a healthy economy with food accessibility. It is worth mentioning that along with the population policies, other cultural, social and environmental policies should be considered. Such a strategy could eventually help in attaining a healthy economy to operate.

\section{Method of Research}

Methodology used in the present abridged article is of qualitative type. In that, various paradigms have been used for fact finding. The method applied in the present study, searched the needs in their natural settings. In fact, finding for the research, the researcher engaged in careful collection of data in a thoughtful manner, and what was in need and relevant, was analyzed. The documentary research applied for data collection include printed and written materials which were widely regarded. The research being a qualitative library type, in that, the researcher had to refer to relevant and related sources; such as books, journals and statistical resources in a thorough way to access the needful information. As a naturalistic inquiry, the researcher could almost reach an in-depth understanding of some social phenomena which could help other social researchers and thinkers in the future as well.

\section{Sustenance of healthy economy}

Sustaining a healthy economy is only possible if housing, food, household budget and education are provided. Under such an atmosphere social management could suitably be fulfilled [4]. This is also worth mentioning that the developed countries also reach economic health through variables such as safety, discipline and social accounting.

The system of healthy economy could only be applicable under the conditions/standards of enough food and housing for all classes of people [5]. To attain the pre-planned objectives, enough investment in terms of time and place need to be applied. Many of the developing countries of the world have put into practice the necessary infrastructural indices so that they could reach the status of a healthy economy.

\section{Healthy economy vs development}

Social, environmental and cultural factors all have an effective impact on a healthy economy, an integration of all could lead to a healthy society. Similarly, healthy economy could be counted as a guardian of development in general. Hence, economic plans, and further economic growth, and also a condition in which social capital is crytstallized, each as agents of healthy economy, play role. In the meantime, creation of a safe environment will be attainable in a society, through the preservation of health in a society [6]. Similarly, accessing appropriate cultural backgrounds, or in other words, reformation of cultural and artistic structure in a society plays as the guardian of health system.

\section{Vulnerability of environment}

Increasing number of urban areas in Africa, Asia and Latin America, as a result of their rapid population growth, poor and weak social accounting and their deteriorating socio-economic conditions, are encountering increasing vulnerabilities. These countries have been facing extensive migrations. Such interactions have had social, economic and cultural impacts on these societies including destructive and negative environmental, social pollution and food shortage. As compared with developed societies, they are prone to a large number of vulnerabilities. The objective outcome of which has influenced different social groups of people in various aspects. Therefore, social accounting of environment will bridge the societies to social health. Such countries are constantly facing migrants to cities who encounter shortage of necessary services and food items. Therefore, applied sociology through social accounting must be used to study the present and future generations with a focus on their needs [7].

\section{Conclusion}

Social accounting challenges conventional accounting and is designed to support and facilitate the pursuit a country's objectives. Such objectives can be manifold, but can typically be described in terms of social and environmental desirability and sustainability, food accessibility etc. [8].

\section{Acknowledgment}

None.

\section{Conflict of interest}

No conflict of interest.

\section{References}

1. (2018) World Population Data Sheet (WPDS), Population Reference Bureau, United Nations, New York, USA.

2. Mellisa B (2017) Fertility Law and Ethics, Fertility Today, USA.

3. Sheykhi Mohammad T (2001) Economic and Social Demography $\left(2^{\text {nd }}\right.$ Edn) Shekate Sahamie Enteshar, Tehran, Iran.

4. Hobbs M (2002) Growing a Healthy Environment, Bulletin on Healthy Economy, New Zealand. 
5. Charles W (2008) Healthy Economy Requires Moral Restraints, 7. Sheykhi Mohammad T (2016) Sociology of Environment, Harir Newsweek, USA. Publications, Tehran, Iran.

6. Ruhm CJ (2006) NBER, Working Paper, Bulletin on Aging and Health, 8. Retrieved (2019) Social Accounting. Number 12102, University of North Carolina, USA. 